\title{
Notas metodológicas para el cálculo de la tasa de ganancia de un capital individual industrial en Argentina a partir de las Memorias y balances ${ }^{1}$
}

\author{
Methodological Notes for Calculating the Profit Rate of an Individual Industrial \\ Capital in Argentina Using Annual Reports and Accounting Balance Sheets
}

Emiliano Andrés Mussi

\begin{abstract}
RESUMEN
El objetivo de este trabajo es presentar una metodología para calcular la tasa de ganancia de un capital individual industrial a partir de las Memorias y balances de las empresas sobre los desarrollos presentados por Marx. A pesar de la importancia que tiene la estimación de la tasa de ganancia en tanto indicador de la capacidad de valorización del capital, pocos estudios avanzaron en el estudio de las problemáticas específicas de su cálculo. En general toman los márgenes como medida de rentabilidad, pero dejan de lado el capital adelantado a valorizar.

En función de nuestro objetivo, el primer apartado del trabajo está dirigido a definir cualitativamente el objeto de estudio. Luego se avanza en una revisión bibliográfica sobre el tema estudiado desde comienzos del siglo XIX hasta la actualidad, para finalmente desarrollar una metodología que contempla la reestimación del capital constante fijo a valorizar, así como de las ganancias obtenidas para determinar la tasa de ganancia del capital individual.
\end{abstract}

Palabras clave: tasa de ganancia, capital individual, stock de capital, rentabilidad, Argentina.

Clasificación JEL: B41, M4, B51, M21.

\begin{abstract}
This paper aims to present a methodology for calculating the rate of profit of an individual industrial capital using annual reports and accounting balance sheets from companies and developments presented by Marx. Despite the importance of the estimation of the rate of profit as an indicator of capital appreciation capacity, few studies have advanced in the study of the specific problems in calculating it. In general they take the margins as a measure of profitability, leaving aside the advanced capital to be valued.

\footnotetext{
1 Fecha de recepción: 10/08/2017. Fecha de aprobación: 21/05/2019.

2 Universidad de Buenos Aires, Argentina. Correo electrónico: emilianomussi@gmail.com. ORCID: 0000-00016183-0081.
} 
Given our objective, the first section of the paper is aimed at qualitatively defining our object of study. Then we proceed with a bibliographic review of the subject being studied from the early 19 th century until today. Finally, we develop a methodology that considers the reestimation of fixed constant capital to be valued, as well as earnings obtained to determine the rate of profit of the individual capital.

Key words: Profit rate, individual capital, capital stock, profitability, Argentina. JEL Classification: B41, M4, B51, M21. 


\section{INTRODUCCIÓN}

La tasa de ganancia constituye un indicador clave al momento de evaluar de la capacidad del capital de valorizarse a sí mismo. Es clave en la medida en que pone en relación al capital a valorizar con el resultado de dicha operación. Por esa razón supera las medidas de rentabilidad del capital que no toman el capital adelantado, sino el capital consumido. Es decir, las medidas basadas en márgenes tanto de ganancias como de costos no pueden dar cuenta del capital como el sujeto concreto de la producción social, en vista de no establecer al capital como premisa y resultado del proceso de valorización (Iñigo Carrera, 2008).

En la actualidad existen diferentes trabajos tanto para la Argentina como para otros países que calculan la tasa de ganancia para el conjunto del capital total de la sociedad en un espacio nacional. A partir del trabajo con Cuentas Nacionales, las matrices de insumo-producto y diversas series estadísticas nacionales, diferentes autores han avanzado, con mayor o menor precisión en sus cálculos, sobre cómo se valoriza el capital social en un país (Shaikh y Tonak, 1997; Duménil y Lévy, 2002; Iñigo Carrera, 2007; Mateo Tomé, 2007; Kliman, 2009; Michelena, 2009; Manzanelli, 2010; Féliz, 2011; Maito, 2013; Kornblihtt, 2015). Sin embargo, por diferentes razones, no se ha avanzando de la misma manera en establecer la capacidad de valorización de los capitales individuales.

En este trabajo nos concentraremos en las discusiones metodológicas para establecer la tasa de ganancia del capital individual industrial a partir de las Memorias y Balances en Argentina. Sólo nos concentraremos en el industrial o manufacturero y quedará para futuros trabajos el análisis de los capitales comercial, bancario o financiero. Esto se debe a que si bien deben valorizarse como cualquier capital, el primero sólo opera en la esfera de la circulación y, por lo tanto, el capital que adelanta por lo general prescinde de un capital constante fijo considerable, que es central en el capital industrial. Lo mismo ocurre con el capital bancario o financiero, donde los activos y pasivos financieros juegan un rol fundamental.

El trabajo está organizado en diferentes secciones. En la siguiente damos cuenta de las determinaciones generales de las diferentes medidas de rentabilidad: los márgenes y la tasa de ganancia. En la tercera hacemos un repaso de los principales trabajos que abordaron la cuestión de la rentabilidad de empresas, desde la valorización de las estancias agropecuarias en el período tardocolonial, pasando por el momento de la acumulación de capital en las décadas de 1960-1979, hasta la actualidad. En la cuarta sección tomamos las principales discusiones sobre el uso de balances para el cálculo de la tasa de ganancia y proponemos una propia. La quinta sección está dedicada al tratamiento de los diferentes índices de precios a la hora de trabajar con los balances. Por último, presentamos las conclusiones de los principales ejes del trabajo. 


\section{Determinación de las medidas de rentabilidad ${ }^{3}$}

\section{Aquellas medidas que no toman en cuenta la rotación del capital (márgenes)}

Una forma de medir la rentabilidad es a través del margen de ganancia o markup. ${ }^{4}$ El margen de ganancia presenta a la ganancia como un porcentaje de los ingresos totales, en cambio, el markup lo hace como un porcentaje que se agrega a los costos. El cálculo de márgenes de ganancia se puede expresar de la siguiente manera:

$$
m p=\frac{K T A^{\prime}-k t c}{K T A^{\prime}}
$$

donde: $\mathrm{mp}=$ margen sobre el precio; $\mathrm{KTA}^{\prime}=$ capital total que surge luego de finalizado el proceso de valorización, $\mathrm{y}$ ktc $=$ capital total consumido.

Este tipo de indicador de rentabilidad no permite dar cuenta del proceso de valorización de capital. En primera instancia porque no avanza en señalar cuáles son las fuentes de donde brota la ganancia. En la fórmula no hay ninguna referencia que permita entender la relación entre la ganancia y el capital que fue adelantado y consumido. Iñigo Carrera (1996: 31) señala que la rotación del capital, es decir, la relación entre el capital como premisa y resultado del ciclo, mediante el capital consumido, aparece degradada en la relación del capital valorizado consigo mismo.

Una aparente superación sería tomar como indicador de la rentabilidad del capital el margen de la ganancia sobre los costos o markup $(\mathrm{mc})$. Se trata de poner en relación el capital valorizado con el capital consumido (ktc):

\footnotetext{
3 En este punto, en líneas generales seguimos el trabajo de Kornblihtt y Dachevsky (2011), punto I.

4 Otra medida de rentabilidad muy frecuente es la Tasa Interna de Retorno (TIR). Es la tasa que iguala el valor presente de los flujos netos de todos los años del horizonte de evaluación con la inversión inicial. Se la podría interpretar como la más elevada tasa de interés que se pagaría por un préstamo que financiara la inversión, si el préstamo con los intereses acumulados a esa tasa dada se fuera amortizando con los ingresos provenientes del proyecto, a medida que éstos van siendo generados durante toda la vida útil del proyecto. La Tasa Interna de Retorno Modificada (TIRM) es utilizada en proyectos donde existe más de un cambio de signo en el flujo de fondos.

Las críticas a estas medidas de rentabilidad son varias. Desde el análisis del cálculo financiero se señala que no permite ordenar proyectos de inversión. Se presume que tanto las ganancias como las pérdidas son reinvertidas a la tasa interna de retorno, lo cual no es seguro que ocurra (De la Fuente, 2011: 612-614). También se marcaron los límites que tiene para dar cuenta de la capitalización de las erogaciones y el desfasaje en la aparición de beneficios (Guadagni, 1973). Pero sobre todo, esta medición busca incluir el costo de oportunidad del dinero sujetando su formulación al ciclo de valorización a interés. Autores como Iñigo Carrera (1996) y Levín y Kicillof (1999) señalaron los límites de la TIR para tratar de manera correcta la rotación del capital fijo. Por esta razón es una medida que no señala la rentabilidad de los capitales individuales.
} 


$$
m c=\frac{K T A^{\prime}-k t c}{k t c}
$$

Sin embargo, esta forma de medir la rentabilidad del capital tampoco logra dar cuenta de las etapas por las que debe atravesar el proceso de valorización de capital (adelantado, consumido y valorizado). En particular, es un cálculo que no presenta el capital adelantado que fue necesario para iniciar el proceso de valorización. Sólo sería correcto si el capital consumido coincidiera con el adelantado, cosa poco probable si se toman en cuenta las diferentes velocidades de rotación del capital fijo y circulante que existen en las ramas de producción (Iñigo Carrera, 2006: 32; Dachevsky, Kornblihtt, 2011: 4; Valenzuela Feijóo, 2009).

Debemos avanzar en una medida de rentabilidad que vincule al capital adelantado con la ganancia. Para eso primero debemos responder, de manera general, a las determinaciones del capital adelantado y la ganancia, y para eso presentaremos el planteamiento desarrollado por Marx (1999).

\section{Las determinaciones de la tasa de ganancia}

La tasa general de ganancia

El capital es la relación social que se establece a partir de la producción social que se realiza de manera privada e independiente. Esta relación social se establece en forma autónoma, sin una regulación consciente, a partir de la compra y venta de mercancías. Lo particular que permite que las mercancías sean igualadas y, por lo tanto, intercambiables, es que son producto del trabajo necesario de la sociedad. De este carácter común surge una diferencia que está dada por el valor de uso de las mercancías.

Mientras las mercancías en general sólo pueden transferir su valor, la fuerza de trabajo es la mercancía capaz de agregar más valor del necesario para su reproducción, un plusvalor. Dicha capacidad se concreta en el proceso de producción y se realiza en la circulación. Recién cuando las mercancías sean vendidas se pondrá de manifiesto si el dinero gastado en comprar las mercancías necesarias para llevar a cabo la producción pudo ser valorizado. Este proceso se puede representar en el siguiente esquema:

$$
D-M_{M P}^{F T}--P P--M^{\prime}-D^{\prime}
$$

donde: $\mathrm{D}=$ dinero, $\mathrm{M}=$ mercancías, $\mathrm{FT}=$ fuerza de trabajo, $\mathrm{MP}=$ medios de producción, $\mathrm{PP}=$ proceso de producción, y $\mathrm{M}^{\prime}=\mathrm{M}+$ ? $\mathrm{M}$ y $\mathrm{D}^{\prime}=\mathrm{D}+$ ? $\mathrm{D}$. 
En este proceso se pueden diferenciar las mercancías que transfieren valor (capital constante) y aquellas que además de transferir agregan un plusvalor (capital variable, la fuerza de trabajo). ${ }^{5}$ Además, dentro del capital constante, una porción del mismo no se transfiere de manera plena a la mercancía producida, sino que transfiere su valor de manera gradual a lo largo de su vida útil. Es el capital constante fijo, constituido en general por maquinarias, equipos de transporte e instalaciones. Por otro lado, otra porción del capital constante sí entra de manera íntegra en la nueva mercancía. Es el capital constante circulante, que está compuesto de materias primas. Junto con la fuerza de trabajo constituyen el capital circulante.

Como ya se anotó, sólo el capital variable es plausible de variar y agregar más valor del necesario para su reproducción. Constituye la única parte del capital adelantado capaz de engendrar la ganancia, debido a que es un agregado no pagado por el capitalista. ${ }^{6}$

Para dar cuenta del proceso de valorización hay que tener en cuenta que el desembolso en fuerza de trabajo (cv) no puede generar valor ni plusvalor sin entrar en relación con los medios de trabajo (ccc) y con los medios de producción (ccf). En ese sentido, es necesario destacar la relación entre el capital total adelantado (KTA) y la porción "excedente" que surge del proceso de valorización. La relación entre el KTA y D', menos el capital consumido son las ganancias (g). De esta manera, el indicador para dar cuenta de la dinámica del capital se expresa en la tasa de ganancia, la relación entre el capital a valorizar y el resultado de dicha valorización:

$$
g^{\prime}=\frac{g}{K T A^{\prime}}
$$

donde: $\mathrm{g}^{\prime}=$ tasa de ganancia, $\mathrm{g}$ = ganancia, $\mathrm{y}$ KTA = capital total adelantado.

Por $g$ se entiende los ingresos obtenidos menos el capital consumido. El capital consumido está formado por la sumatoria de la porción consumida del capital fijo en un período definido y todo el capital circulante. Mientras que por

\footnotetext{
5 Marx señala que "La fuerza de trabajo se cuenta como valor, pero en el proceso de producción funciona como creadora de valor" (Marx, 1999, t. III: 33). Además, apunta que en el valor de producto por un lado reaparece el valor del capital constante, que sólo existía como parte constitutiva del capital adelantado, y por otro lado las jornadas laborales durante la producción mercantil constituyen un valor nuevo.

6 Sólo la fuerza de trabajo consumida en actividades que producen nuevos valores. Es decir, en los que opera una transformación física o espacial de la mercancía. Otras actividades necesarias para la reproducción del capital, pero que no transforman físicamente a la mercancía, no agregan valor. Existen numerosos debates sobre el carácter del trabajo productivo e improductivo, y la posibilidad de separar ambos en términos empíricos. Entre ellos el de Moseley (1997) y el de Shaikh y Tonak (1997).
} 
KTA se debe considerar todo el capital fijo y la cantidad inicial de capital circulante. Es decir, sólo una porción del total consumido necesario para el primer ciclo del período bajo análisis. Por ciclo se entiende las veces que se completa D-D'.

$$
\begin{gathered}
g=P-K f c-K c c-K v c \\
K T A=K f a+\frac{K c c+K v c}{n}
\end{gathered}
$$

donde: $\mathrm{P}=$ producto $\mathrm{Kfa}=$ capital fijo adelantado $\mathrm{Kcc}=$ capital circulante consumido; Kvc = capital variable consumido, $\mathrm{y} n$ = velocidad de rotación.

\section{Tasa promedio de ganancia y tasa de ganancia del capital individual}

La tasa general de ganancia es el indicador que condensa el movimiento del capital total en la medida en que pone en relación el trabajo objetivado, pretérito (el capital constante), el trabajo presente (en el capital variable), al mismo tiempo que da cuenta de la parte paga del trabajo vivo (el valor de la fuerza de trabajo) como impaga (el plusvalor). ${ }^{7}$ El capital total se presenta en la forma de una multiplicidad de capitales que compiten entre sí por apropiarse una porción del plusvalor total producido desde la forma de ganancia para lograr su valorización y continuar con su ciclo de reproducción. Ahora bien, existen ramas de producción con una mayor tasa de plusvalor (plusvalor/valor), según la proporción entre trabajo vivo y muerto. Sin embargo, esta diferencia se anula mediante la movilidad del capital intra e interramas por la vía de la competencia entre los diferentes capitales individuales.

El movimiento de los diferentes capitales orientados por la búsqueda de maximizar sus ganancias nivela de manera paulatina las tasas de ganancias de diferentes ramas en torno a un promedio. ${ }^{8}$ Cada capital individual tiende a ganar no en función de la capacidad de producir plusvalor, sino en proporción al capital total adelantado.

\footnotetext{
Para Marx, "La tasa de ganancia descubre en qué medida se ha valorizado el capital o su grado de valorización [...] El capital presenta una relación consigo mismo. Una relación en la cual se distingue como suma originaria de valor, de un valor nuevo puesto por el mismo" (Marx, 1999, t. III: 54-56).

8 El vínculo entre la tasa de ganancia del capital individual (tasa uniforme) y la tasa de ganancia general como unidad y pluralidad al mismo tiempo en cuanto formas sociales del valor que se valorizan a sí mismas fueron tratadas de manera minuciosa por Robles Báez (2013).
} 
La tasa de ganancia promedio existe como una tendencia general. Por un lado, la búsqueda incesante de maximizar las ganancias por la vía de reducir los costos unitarios de producción lleva a mecanizar los procesos de trabajo como la forma concreta en que se expresa el aumento de la plusvalía relativa, modificando de manera permanente la relación entre capital variable y constante de cada rama. Al interior de cada rama aparece una diversidad de capitales con estructuras de costos y capitales desembolsados diferentes.

La tasa general de ganancia se expresa en la tasa de ganancia particular de cada capital individual. Por esa razón encontramos empresas que obtienen una ganancia extraordinaria arrojando como resultado una tasa de ganancia por encima de la media, otras empresas que se ubican torno a la tasa promedio y empresas más ineficientes que tienen un menor grado de valorización y por lo mismo obtienen una tasa por debajo de la tasa promedio. Esta incapacidad de valorizarse a la tasa promedio le implicará una menor capacidad de acceder al crédito y verá profundizada su tendencia a la quiebra. ${ }^{9}$

En suma, habiendo revisado las discusiones analíticas sobre las determinaciones de la valorización del capital individual estamos en condiciones de avanzar en el estudio de la bibliografía específica que se ha enfrentado al problema concreto de cuantificarla en Argentina.

\section{Mediciones de rentabilidad en Argentina a partir de los balances de empresas}

Las mediciones de rentabilidad en la Argentina a partir de los balances son escasas. En particular porque en una economía inflacionaria los estados contables no reflejan de manera fidedigna la situación financiera de la empresa, y los ajustes por inflación son asimismo aún más escasos. Sin embargo, en los últimos años han aparecido diversos trabajos que abordan la problemática de la rentabilidad del capital individual a partir de balances. No sólo estudios situados en la actualidad, sino también para el período de los 1950-1969, e incluso trabajos que abordan este problema en las estancias agropecuarias en el Río de la Plata a fines del siglo XVIII y comienzos del siglo XIX.

Estos últimos trabajos comenzaron a ser comunes desde la década de 19801989 y hasta la actualidad. Los trabajos de Halperin Donghi (1975) y Brown (1978) calculaban la rentabilidad de la estancia en términos de márgenes sobre costos. En su estudio sobre la Estancia de Clemente López Osornio, Amaral (1989) superó

\footnotetext{
9 Iñigo Carrera (2008, cap. V) avanza en mostrar las determinaciones del pequeño capital y su vínculo con el capital industrial medio.
} 
esta forma de estimar la rentabilidad afirmando que aquellos autores dejaban de lado el "capital invertido"10 inicial que había que valorizar. Según su estimación, la "tasa de utilidad" habría sido del $5 \%$ en el período analizado, señalando entonces a la estancia tardocolonial rioplatense como una empresa agraria que valorizaba su capital. El principal problema de este estudio es que contabiliza al interior de la utilidad total una "utilidad neta no realizada", definida como la diferencia del valor del inventario respecto del año anterior. El otro inconveniente es que para calcular el monto del capital a valorizar ("monto de inversión inicial") toma el capital del año anterior (kt-1), pero le adicionaba el circulante consumido durante el año (los egresos), sin tener en cuenta la rotación del capital.

En un artículo reciente sobre la estancia Los Portugueses para el período 1802-1809, desde una postura marxista, Flores (2015) critica estas estimaciones sosteniendo que la "falencia general es conceptual". El trabajo propone una perspectiva metodológica diferente, sostenida en que como el capital es una relación social, al mencionar la inversión inicial habría que considerar que ésta ya es resultado del trabajo humano, es decir, "un valor creado por el productor directo y agregado al capital inicial” (Flores, 2015: 102). Avanza en criticar que el inventario tasado no constituye de manera lineal la inversión inicial poque habría que depurarlo del consumo personal del propietario de la estancia (Flores, 2015: 102), pero presenta dos errores ${ }^{11}$ principales que parten de no comprender que si bien el capital es una relación social, lo es en la medida en que el trabajo social es realizado de manera privada e independiente. ${ }^{12}$ Por un lado, al señalar que el

${ }^{10}$ Djenderedjian (2003) realiza un cálculo similar basado en el trabajo de Amaral.

${ }^{11}$ El trabajo presenta, además, diferentes criterios discutibles a la hora de estimar la ganancia. En el cuadro 12 estima ganancia de la estancia Los Portugueses (1802-1809). Para eso toma los ingresos por cueros, ganado en pie y mulas, y resta el capital consumido durante esos años (los "gastos", aunque para el caso de los esclavos y los medios de producción de manera llamativa lo llama "inversión”). Ahora bien, para establecer el capital fijo consumido nos remitimos al cuadro 9 "Inversión en medios de producción en Los Portugueses (1802-1809). Aquí el autor toma el precio adelantado al comenzar las actividades y lo prorratea para los ocho años en estudio. Ese prorrateo no es más que establecer la vida útil y el patrón de consumo de cada bien. Lo hace a partir de considerar el valor de cada bien pagado en 1789 (cuando el dueño poseía la escritura de la Estancia) y 1814 cuando cambió de dueño (Flores, 2015: 115). Aquí se presentan dos problemas. El primero es que incluye la tierra como un medio de producción. El segundo es que le adjudica una vida útil de 25.9 años. Más allá de la discusión de cómo tomar los terrenos para el cálculo del capital total adelantado, que lo desarrollaremos más adelante y que en sí mismo amerita un trabajo aparte, lo importante aquí es que se está considerando que la tierra, luego de 26 años, perdería de manera íntegra su valor. Esto implica una magnificación del capital consumido, y por lo tanto una subestimación de la ganancia arrojada por la estancia.

12 "La estructuración cuantitativa del organismo social de producción — que presenta sus membra disiecta [miembros dispersos] en el sistema de la división del trabajo - es tan naturalmente fortuita como la cualitativa. Nuestros poseedores de mercancías descubren, pues, que la misma división del trabajo que los convierte en productores privados independientes hace que el proceso de producción y las relaciones suyas dentro de ese proceso sean independientes de ellos mismos, y que la independencia recíproca entre las personas se complemente con un sistema de dependencia multilateral y propio de cosas" (Marx, 1999: 131). Veáse asimismo (Iñigo Carrera, 2007). 
capital adelantado es resultado del trabajo humano pretérito que "se agrega" al capital inicial es no tomar en cuenta la forma históricamente específica que toma el trabajo humano en la sociedad, donde impera el modo de producción capitalista. Por otro lado, a pesar de señalar que no es ganancia, ${ }^{13}$ Flores considera dentro de la utilidad final la "utilidad neta no realizada", tal como sugiere Amaral. Pero si bien se podría contabilizar la utilidad producida, tal como señalamos en el acápite anterior, sólo puede considerarse como ganancia en la medida en que el valor portado en la mercancía se haya realizado en el ámbito de la circulación. Es en ese momento de metamorfosis $\left(\mathrm{M}^{\prime}-\mathrm{D}^{\prime}\right)$ cuando la mercancía producida por un trabajo privado demuestra su carácter social. El autor parece sugerir que el valor producido por el trabajo humano es directamente social. Este problema se traslada a la hora de computar la ganancia. Para el período 1806-1808, la utilidad no realizada o "valorización" representa $46 \%$ de la "utilidad final", lo cual distorsiona todo el cálculo (cuadro 14: 121).

Para el período conocido como Industrialización por Sustitución de Importaciones encontramos diferentes trabajos que atienden las dificultades a la hora de calcular la rentabilidad del capital industrial a partir de los balances. Varios economistas nucleados en el Instituto de Economía y Finanzas de la Universidad Nacional de Córdoba durante la década de 1970-1979, ajenos a la tradición marxista, hicieron un esfuerzo por sistematizar los revalúos y ajustes necesarios para medir la tasa de ganancia de múltiples capitales individuales durante la década de 1960-1969 en Argentina. Los trabajos de FIEL (1971), Petrei (1973), Arnaudo (1975), así como el comentario de De Pablo (1975) y Guerberoff (1977) constituyen un insumo insoslayable para el cálculo de la tasa de ganancia empresarial en países con inflación sistemática. Allí se presentan discusiones metodológicas para el revalúo del stock de capital, los inventarios, las ganancias y las deudas.

Lo particular del trabajo de FIEL (1971) es que se ocupa de la rentabilidad de las empresas a partir del financiamiento recibido según el tamaño de las mismas. El trabajo de Petrei (1973) presenta la novedad de revaluar el stock de capital a partir del método de inventario permanente y calcular una tasa de ganancia industrial, ${ }^{14}$ continuando con la metodología de Harberger (1969) para la estimación de la tasa de ganancia industrial en Colombia. Tomando una muestra de casi 600 empresas para el período de 1961 a1967 da cuenta de cómo la inversión tendió a orientarse en aquellas ramas en las que la tasa de ganancia se mantuvo estable a lo largo del período. Arnaudo (1975) presenta diferentes formas de

\footnotetext{
13 "De todos modos, valga la aclaración de que la valorización no es aún ganancia $[\ldots]$ ya puede ser vendida [...]" (Flores, 2015: 121).

${ }^{14}$ Es interesante la crítica de De Pablo (1975) a la estimación de Petrei (1973) sobre la revaluación de los inventarios y su impacto en la ganancia empresarial.
} 
calcular la tasa de ganancia industrial, señalando en cada caso los ajustes necesarios a aplicar para eliminar las distorsiones ocasionadas por la inflación. Su principal objetivo es dar cuenta de los problemas que acarrea no ajustar por inflación los cálculos de los balances. Un punto interesante es que señala cómo en contextos inflacionarios se licúa parte de las deudas que contrae el capital industrial. Continuando con el método aplicado por Petrei, y discutiendo aspectos parciales del mismo, Guerberoff (1977) analiza la rentabilidad de las empresas argentinas para el período 1949-1967 con miras a señalar la dinámica de las empresas de capital nacional y extranjero, antes y después de la caída del peronismo en 1955.

Si bien en general estos trabajos revalúan el stock de capital y los rubros necesarios de los balances, y aportan elementos que retomaremos en los acápites siguientes, podemos apuntar que no toman el capital adelantado, sino que relacionan las ganancias del año $t$ con el capital ya valorizado del año $t$. Este punto fue señalado en el trabajo citado de Amaral y por Kornblihtt (2010) en el trabajo sobre las bases de acumulación de Siderca, empresa argentina miembro del grupo Techint, productora de tubos sin costura que ganan presencia internacional en la década de 1990-1999. Éste último presenta una medida del stock de capital que replica el capital físico de Petrei (1973), aunque sin los revalúos de los bienes de uso, donde se destaca que al momento de tomar el capital adelantado es necesario tomar el informado en los balances del año anterior y relacionarlo con la ganancia del ejercicio en cuestión.

Al mismo tiempo, estos trabajos no incorporan en sus cálculos el capital circulante variable adelantado, coherente con el punto de vista neoclásico que retoman. Desde esta posición, la ganancia no brota del trabajo impago creado por la fuerza de trabajo, sino que surge de la retribución del factor capital en la función de producción. Esto constituye la medida clásica del "retorno sobre el capital" (return on capital, ROC) (Samuelson y Nordhaus, 2002). Plantea como denominador al stock de capital y no al capital consumido como los márgenes, aunque como vimos el capital adelantado aparece ya valorizado al no tomar el del año anterior. Estas medidas toman la utilidad sobre el patrimonio neto (Return on equity, ROE) o el activo (Return on assets, ROA) (Adrogué y Anido, 1998), que son utilizadas en informes elaborados por diferentes oficinas estatales, como el caso de la Sindicatura General de Empresas Públicas para empresas públicas (SIGEP, 1988)..$^{15}$

El trabajo ya clásico de Sourrouille (1980: 215) para la rama automotriz en Argentina también estima la rentabilidad para cada una de las empresas auto-

\footnotetext{
${ }^{15}$ Aquí vale aclarar que el patrimonio neto es la diferencia entre el activo y el pasivo en una empresa, y su análisis se corresponde con el punto de vista del propietario del capital.
} 
motrices durante la década de 1960-1969, a partir del patrimonio como capital adelantado, pero reestimándolo para corregir las distorsiones inflacionarias. Las altas tasas de inflación tienden a subestimar de manera progresiva el patrimonio de los capitales en los balances contables, por eso lo recalcula a partir de calcular las variaciones anuales del patrimonio y convertirlos a dólares al tipo de cambio oficial. Sin embargo, este ajuste no contempla dos puntos importantes.

Como señala Fitzsimons (2014: 97-98), en primer lugar al usar el tipo de cambio nominal y no el de paridad en la capacidad de las monedas de representar valor, podría sobreestimar las variaciones del patrimonio, siempre que la moneda se encuentre sobrevaluada. ${ }^{16}$ Más importante aún es que toma el patrimonio y las ganancias del mismo año, por lo tanto el patrimonio ya aparece valorizado. No está contemplando en qué medida se valorizó el patrimonio que se adelantó. Fitzsimons reestima la tasa de ganancia de las automotrices a partir de restarle al patrimonio de cada año las utilidades de ese año, y obtener de esa forma el capital adelantado a valorizar en cada año. ${ }^{17}$

Bil y Bastida Bellot (2016) también estiman la rentabilidad de las terminales automotrices y autopartistas en Argentina para la década de 1960-1969 a partir de balances. Superan a Sourrouille al tomar como capital adelantado el patrimonio o el capital reproductivo del año anterior, sin embargo toman como referencia las cifras de Sourrouille (1980), a pesar de los límites que señalamos. ${ }^{18} \mathrm{La}$ forma en que construyen las series tiene serios límites. Por un lado, señalan como un "hito" las dificultades de trabajar con balances en contextos de alta inflación, tal como advirtieron Petrei y Guerberoff, pero en vez de superarlas a partir de reestimar los bienes de uso con el Método de Inventario Permanente, como hacen esos autores, sólo deflactan las cifras con un índice de precios al consumidor que coincida con la fecha de cierre del balance. Por otro lado, toman los "terrenos"

\footnotetext{
${ }^{16}$ Según las estimaciones de Iñigo Carrera (2007: 43) el tipo de cambio de paridad permanece sobrevaluado prácticamente durante toda la historia económica argentina contemporánea. Para su metodología, Iñigo Carrera (2007: 31-35).

${ }^{17}$ El autor cita el caso de la estimación de la tasa de ganancia para Ford en 1961, donde Sourrouille toma las utilidades tanto en el numerador como en el denominador: "Para tomar un ejemplo concreto, Ford Motors Argentina incrementó su patrimonio prácticamente desde cero hasta veinte millones de dólares en 1960; la mitad de estos aportes provinieron del exterior bajo la forma de equipos y partes y el resto (otros diez millones) fueron generados por utilidades obtenidas en el año. En 1961 ganó nueve millones, importe equivalente al incremento total del patrimonio". Esto nos muestra que la tasa de ganancia que Sourrouille presenta para Ford de 1961, de $31 \%$, surge de relacionar la ganancia de nueve millones con un patrimonio de 29 , que incluye los nueve de ganancias de ese año $(31 \%=9 / 29)$. Como veremos enseguida, nuestro cálculo considera como capital únicamente los veinte que forman parte del capital adelantado, por lo tanto la tasa de ganancia de ese año es de casi $45 \%(44.93 \%=9 / 20)$ " (Fitzsimons, 2014: 98).

18 “[...] nuestras mediciones son en cierta medida compatibles con las que consiguiera Sourrouille. [...] El autor sitúa los comienzos de la crisis de la actividad a mediados de los sesentas, lo que puede confirmarse con los cálculos que realizamos en base a las empresas menos competitivas $[\ldots](\mathrm{s} / \mathrm{n})$ ".
} 
como capital constante fijo al no depurarlos de los "bienes de uso". Según las normas contables los terrenos no se amortizan, por lo que de esta forma magnifican el capital adelantado y subestiman la tasa de ganancia. Como se verá más adelante, una forma de tratarlos es a manera de alquiler adelantado, por lo tanto, no como una parte del capital constante fijo sino del circulante. Además, al tomar sólo los bienes de cambio del año anterior como capital constante circulante adelantado dejan de lado que una forma de existencia del mismo son las disponibilidades con las que cuenta la empresa para comprar insumos en el momento en que comience el ejercicio. De este modo subestiman el capital adelantado, sin contar que tampoco contemplan el capital variable adelantado al no estimar la rotación del capital circulante, que redunda en una sobreestimación de la tasa de ganancia.

También existen estudios que trabajan la rentabilidad del capital industrial aplicado a rama minera, en particular la petrolera, con el objetivo de estimar la renta de la rama. Los trabajos de Mansilla (2006), Barrera (2013) y Recalde (2012) realizan una estimación de la renta petrolera basada en los márgenes sobre costos tanto del sector como de las grandes empresas argentinas considerándolas como ganancia normal. No consideran el capital adelantado a valorizar y, por lo tanto, la tasa de ganancia.

Un intento por superarlos es el de Bil y Farfaro Ruiz (2012) quienes estiman la renta petrolera en Argentina a partir de estimar la tasa de ganancia de YPF con base en sus balances. Sin embargo, tal como señalan Kornblihtt y Dachevsky (2017) en su estimación de la renta petrolera, es necesario no descontar las amortizaciones de las reservas petroleras de las ganancias para no distorsionar el cálculo. En la contabilidad de la empresa, las reservas no están incluidas en los activos, pero sí contemplan la depreciación. De esta forma reducen la magnitud de la utilidad final, subestimando la tasa de ganancia.

Por último, también se desarrollaron modelos de aplicación concreta para el cálculo de la tasa de ganancia de un capital individual. Uno de ellos es el elaborado por Iñigo Carrera (1996). En él se desarrollan puntos importantes sobre la valorización del capital individual por los diferentes ciclos de rotación del capital y su vínculo con el capital total de la sociedad. Se aplicó en numerosos trabajos que examinan la tasa de ganancia en el sector agrario, entre ellos, el de Bas y Carllinni, (1987) y el de Iñigo Carrera (1992), y para el cálculo de la tasa de ganancia de capitales industriales siderúrgicos brasileros y surcoreanos (Grinberg, 2011: 184).

Otro modelo para el cálculo de la tasa de ganancia empresarial que contempla la rotación del mismo es el elaborado por Levín y Kicillof (1999) a partir del denominado simulador de impacto ganancial. Utilizando un modelo de rotación de capital calculan la tasa de ganancia correspondiente a una cronoestructura determinada. Un problema que presentaba el modelo es que no introduce 
el capital fijo adelantado, sino el consumido. ${ }^{19}$ Por lo tanto, la tasa de ganancia arrojada está sobreestimada.

Son numerosos los trabajos que toman márgenes como medida de rentabilidad, tanto sobre las ventas como sobre los costos a partir de balances para empresas en Argentina. Como ya se señaló, aunque no dan cuenta del proceso de valorización del capital, estas medidas de rentabilidad son más frecuentes. Por esa razón la selección de trabajos tampoco es exhaustiva.

El Área de Economía y Tecnología de la FLACSO ha publicado numerosos trabajos sobre la industria y la economía Argentina en los que con frecuencia se presentan estimaciones de márgenes sobre ventas a partir de los balances de empresas seleccionadas, en general de la cúpula empresaria. Tal es el caso de Azpiazu y Schorr (2010), quienes señalan el contraste entre la rentabilidad durante la década de 1990-1999 y el crecimiento de los 2000. También el trabajo de Pérez Artica (2009) mide el margen sobre ventas a partir de los balances de tres empresas de la rama siderúrgica. Con el análisis de otros indicadores señala cómo crece la rentabilidad de estas empresas a partir de la devaluación del 2002. Castellani (2009) utiliza este tipo de márgenes para dar cuenta de la aparición de ámbitos privilegiados de acumulación de capital en la última dictadura militar. Por último, el trabajo de Arnaudo (1965) utiliza una muestra abierta de en promedio 232 empresas para diferentes ramos de la producción, y en él discute que la inflación del período se debe a un aumento de los márgenes de utilidad.

El estudio de Agostino tiene la intención de medir la tasa de ganancia, sin embargo, a pesar de que menciona colocar como denominador el capital total adelantado para el cálculo de la tasa de ganancia (Agostino, 2015: 60), toma el capital consumido. De esta manera elabora una medida de margen sobre costos (costos de producción, gastos de administración y comercialización) (Agostino, 2015: 68).

\footnotetext{
${ }^{19}$ En sus términos, a la hora de definir el capital fijo lo hacen como "capital fijo = porcentaje pagado al contado del capital fijo/vida útil promedio" (Levín y Kicillof, 1999: 9).
} 


\section{Componentes empíricos de la tasa de ganancia individual ${ }^{20}$}

\section{Limitaciones en el uso de la información de los balances contables}

Podemos encontrar dos tipos de distorsiones en la información presentada en los balances. Por un lado está presente la distorsión que produce la pérdida del poder adquisitivo de la moneda a partir de la inflación. Para este tipo de distorsiones se llevaron a cabo diferentes procedimientos para corregirlos que se detallan más adelante.

Por otro lado, las distorsiones que surgen de declaraciones distorsionadas intencionalmente por las empresas, en particular para eludir impuestos. Para este tipo no fue posible corregirlas. Entre ellas se encuentran ventas no declaradas, sobrefacturación de importaciones, subfacturación de exportaciones, remisión de utilidades al exterior con la apariencia de pagos de intereses sobre préstamos, falsos pagos por regalías y honorarios, aportes de capital disimulados con la forma de préstamos, capitalización de patentes y marcas, entre otros (Guerberoff, 1977: 494).

Esta es una limitación general de todos los datos disponibles en el país, incluidos los censales. En la totalidad de estos mecanismos la tasa de ganancia estimada constituye una subestimación de la efectiva. Por esa razón De Pablo (1975) señala que lo que se está presentando no es la rentabilidad real, sino la rentabilidad informada, ajustada por inflación.

El capital constante fijo adelantado

En las cuentas nacionales, el capital constante fijo hace referencia al stock de capital. En el balance de una empresa, ese rubro aparece con el nombre de "bienes

\footnotetext{
${ }^{20}$ Una aclaración es pertinente. La tasa de ganancia en general está asociada a la teoría marxista, donde las categorías se estructuran a partir del valor. Sin embargo, la tasa de ganancia no mide el valor producido, porque el valor en cuanto tal no se puede medir, sino que mide la ganancia apropiada, es decir, el valor transformado en precios de producción. En este punto, consideramos que no es posible considerar los tiempos de producción en términos de valor, tal como hacen los sraffianos o Shaikh (2006). Tampoco es posible reducir las magnitudes de valor al trabajo incorporado en las mercancías como los partidarios de la Expresión Monetaria del Tiempo de Trabajo (MELT por sus siglas en inglés). Pretender alguna medición similar parte de no considerar que los productos del trabajo asumen la forma de mercancías porque son producidos de manera privada e independiente, y que por lo tanto, no es posible dar cuenta de la expresión monetaria de los tiempos de trabajo.
} 
de uso" o "plantas, propiedades y equipos" que se encuentra dentro del Activo. ${ }^{21}$ Este rubro da cuenta de todas las instalaciones industriales, edificios, maquinaria y equipos, herramientas y vehículos con los que cuenta la empresa para llevar a cabo su proceso de producción. Informa no sólo aquellos ítems que tiene instalados y en funcionamiento, sino también los equipos que fueron comprados y aún en funcionamiento (es decir, que están "en viaje") o las construcciones que están en proceso. Este stock de las amortizaciones correspondientes se presenta neto, a precios de cada año. Por lo tanto está expresado en históricos corrientes. En términos generales, para poder construir una serie en el tiempo de la evolución de los bienes de uso es necesario revaluarlos a precios históricos reales. En particular en Argentina este problema se hace más evidente debido a las altas tasas de inflación con las que cuenta históricamente (Vitelli, 1986). ${ }^{22}$

Esto se hace evidente desde el momento en que las amortizaciones en el balance se calculan a partir de los valores originales o históricos a los que com-

${ }^{21}$ Bienes de uso: "Son aquellos bienes tangibles destinados a ser utilizados en la actividad principal del ente y no a la venta habitual, incluyendo a los que están en construcción, tránsito o montaje y los anticipos a proveedores por compra de estos bienes. Los bienes distintos a Propiedades de Inversión afectados a locación o arrendamiento se incluyen en Inversiones, excepto en el caso de entes cuya actividad principal sea la mencionada", en Resolución Técnica (RT en adelante), num. 9 de la FACPCE, cap. III: “Estado de situación patrimonial”, punto A.5. (texto S/RT $31 / 2011)$

${ }^{22}$ En la actualidad los balances se presentan a precios corrientes y constantes en caso de realizar comparaciones con años anteriores. Aun así, la Federación Argentina de Consejos Profesionales de Ciencias Económicas (FACPCE), en la RT, núm. 6, resuelve como aplicación obligatoria reexpresar las partidas contables correspondientes en moneda homogénea. El índice que debe emplearse es el índice de precios internos al por mayor (IPIM) del INDEC (IV.B.5, texto S/RT 249/2002). De esta forma, los rubros del balance están presentados en pesos constantes de cada año. Para poder tener series comparables en el tiempo es necesario reexpresarlos en una moneda homogénea. Para eso, proponemos tomar el índice de precios al consumidor (IPC), ya que consideramos que refleja de mejor manera la pérdida del poder adquisitivo de la moneda.

a. Stock de capital

A la hora de revaluar el stock de capital Petrei (1973) toma los índices de precios de los bienes de capital para cada uno de los rubros. Esto implica utilizar seis índices diferentes con el fin de llevar el stock de precios históricos corrientes a precios corrientes o de mercado constantes. Sin embargo, Guerberoff (1977: 503) señala que utilizar un índice para cada rubro de capital no soluciona el problema debido a que al interior de cada rubro existe una gran heterogeneidad de los bienes, lo cual implica que cada uno tenga una evolución de los precios diferentes. Este mismo criterio es seguido por la Agencia Nacional para el Desarrollo Económico (NEDO por sus siglas en inglés) (1973). La diferencia entre los dos estriba en que Guerberoff decide utilizar un índice de precios implícitos a la inversión y la NEDO un índice de precios al consumidor. De esta forma, Guerberoff revalúa el stock llevándolo a precios corrientes, de mercado o de reposición constantes. Sin embargo, Iñigo Carrera (1996) señala que la valuación del stock a precios corrientes corresponde al capital total de la sociedad, mientras que para los capitales individuales, en tanto masas privadas concretas de valor, su stock debe considerarse en términos históricos constantes.

a. Ganancias

En caso en que la fecha de cierre del ejercicio no coincida con la fecha de fin del año calendario, Guerberoff (1977) propone otro ajuste para las ganancias para poder expresar las utilidades a precios de fin de año. Sugiere aplicar la tasa de inflación observada entre la fecha de cierre del ejercicio y el fin del año al valor de las utilidades corregidas. 
praron los bienes, ${ }^{23}$ que luego no se actualizan año con año a partir de las variaciones de los precios. Por lo tanto se subestima el valor neto de los bienes de uso y del consumo del capital fijo, y se sobredimensionan las ganancias del ejercicio. Este problema de esta distorsión se intenta corregir con revalúos contables periódicos. ${ }^{24}$

Los revalúos contables son llevados a cabo por peritos que intentarán llevar a precios de mercado el valor de los bienes en función de la capacidad de producir que éstos tengan. Sin embargo, no resuelven el problema en la medida en que la regularidad con la que se aplican es arbitraria, según lo habiliten las autoridades nacionales. ${ }^{25}$ Este punto genera que a los fines de lograr una evolución histórica de los valores de los bienes de uso, el hecho de que durante un período el valor de los bienes esté distorsionado y luego sea ajustado, provoca una distorsión imposible de sortear, si no es con una reestimación completa del stock de capital fijo de la empresa. ${ }^{26}$

${ }^{23}$ A la hora de contemplar las amortizaciones es importante considerar el criterio que usan las normas contables. Éstas distinguen tres clases de bienes de uso: a) Bienes no sujetos a depreciación ni agotamiento, por ejemplo: terrenos; b) Bienes sujetos a depreciación pero no a agotamiento, por ejemplo, edificios, instalaciones, maquinarias, rodados, etc.; c) Bienes no sujetos a depreciación pero sí a agotamiento, por ejemplo, minas, canteros, bosques, etc. (Garay y Vangieri, 2013).

${ }^{24}$ Según las normas contables, en caso de revaluación deberá indicarse si la misma ha sido practicada "con personal propio o si se han utilizado los servicios de un tasador o especialista en valuaciones que reúna las condiciones de idoneidad y de independencia respecto de la entidad", y se detallarán "los métodos y las hipótesis significativas utilizadas en la estimación del valor razonable de los bienes revaluados", RT, núm. 9 de la FACPCE, cap. VI, "Información complementaria”, punto C.9 (texto S/RT 31/2011).

En la RT, núm. 17, en la sección 5.11.1.1.2.3, "Frecuencia de las revaluaciones", se establece que "las revaluaciones se harán con una regularidad que permita asegurar que el importe contable no difiera significativamente del valor razonable a la fecha de cierre del período o ejercicio". En la interpretación que realizan Parada y Errecaborde de esta RT mencionan que por "valor razonable del bien revaluado" debe considerarse el importe "que la entidad recibiría por vender el activo en cuestión ("precio de salida"), sin deducir los costos de la transacción, pero sí los costos de transporte —si existieran —, dado que el valor razonable depende de la ubicación del bien” (Parada y Errecaborde, 2015: 85).

${ }^{25}$ En la actualidad, las empresas reclaman revalúos contables debido a que en general terminan pagando más impuestos al crecer la masa de dinero, y continuar con parámetros de liquidación atrasados. Iprofesional, 11-08-2014. Link: https://goo.gl/rzPwjF. En vista de que el revalúo también afecta la situación patrimonial de la empresa, le da la posibilidad de acceder a mejores créditos. Iprofesional, 2-8-2013. Link: https://goo.gl/PKtdSk.

En marzo de 2015 la IGJ emitió una norma que permite una revaluación del stock luego de diez años de inflación, sin lugar a actualizar el valor de los bienes. Ver El Cronista 5-3-2015, en: https://goo.gl/Fw4uSh. Revisados $24 / 05 / 2017$.

${ }^{26}$ En el exhaustivo y ya citado informe de FIEL (1971) sobre la rentabilidad y la financiación de las empresas durante 1961-1969 lo señala de esta manera: "Al estudiar la evolución de los bienes de uso de los sectores industriales, consideramos que no es posible, con las cifras provenientes de los balances, efectuar comentarios sobre el valor total invertido, ya que su valuación está afectada particularmente por el proceso inflacionario, por ser bienes durables. [...] [Tampoco] sería válido un análisis comparativo de importancia relativa de valor de bienes de uso por cuanto el revalúo, al ser optativo, distorsiona en forma desigual y significativamente las cifras y limita las posibilidades de su análisis. [...] Se produce un efecto adicional del revalúo en el sistema contable sobre las depreciaciones que, al calcularse sobre mayores valores, crecen arbitrariamente [...]" (t. II: 18). 
Otro elemento que es necesario tener en cuenta a la hora de no considerar el valor de los bienes de uso, tal como se presentan en el balance, es que, como ya se anotó, éstos incluyen maquinarias y vehículos que fueron comprados por la empresa, pero que aún no ingresaron en el proceso de producción. Por lo tanto, estos bienes aún no están transfiriendo su valor al producto elaborado. Lo mismo ocurre con los edificios e instalaciones industriales que se encuentran en construcción: aún no entran en la fase de producción y por lo tanto no deben ser considerados. Un punto importante son los terrenos sobre los que se asienta la planta de producción. Desde el punto de vista contable, no se amortizan porque se considera que no sufren un desgaste. Si bien estos terrenos no son producto del trabajo humano, se podría tomar su valor total ajustado por la tasa de interés para estimar un alquiler del mismo y que entre en la valorización del capital como capital constante circulante consumido. ${ }^{27}$

\section{La revaluación del stock con el Método de Inventario Permanente (MIP)}

La revaluación del stock con el MIP es una forma de resolver los inconvenientes que presentan los bienes de uso valuados a precios históricos corrientes. Este método consiste en la revaluación del stock por la vía de acumulación de las inversiones pasadas depreciadas. Esto constituiría el capital constante fijo adelantado (ccfa). Para calcularlo es necesario elaborar series de inversión para cada uno de los rubros de bienes, según la vida útil de cada uno. La fórmula para el cálculo del Método de Inventario Permanente es la siguiente:

$$
R_{t}=\sum_{F}^{t} \frac{p t}{p i} I_{i}[1-(t-i) d]-\sum_{F}^{t} V_{i}
$$

\footnotetext{
${ }^{27}$ Los terrenos de la empresa los descartamos del cálculo del stock de capital debido a que no sufren una amortización. Por lo tanto, no transferirían su valor al producto de valor generado. De consignarlo en su totalidad año a año se estaría magnificando el volumen del capital fijo adelantado con una consecuente menor tasa de ganancia. La posibilidad aquí considerada es tomar el valor del terreno prorrateado en el tiempo ajustado por la tasa de interés y obtener así un valor similar al de un alquiler. Este valor podría ser considerado como capital constante circulante adelantado. Esta es la forma en que lo computa Engels para el cálculo de la tasa de ganancia de una hilandería de algodón en 1871 (Marx, 1999, t. III: 89). Otra posibilidad sería calcular la tasa de ganancia con y sin terrenos y evaluar el peso que tiene en la misma para luego incorporar esa magnitud en el cálculo del capital consumido.
} 
Para $\mathrm{F} \leq \mathrm{i} \leq \mathrm{t}$, donde: $\mathrm{R}$ = activo fijo valuado a precios históricos constantes; $\mathrm{F}=$ año de fundación de la firma; $\mathrm{i}$ = año en el que se llevó a cabo la inversión; I = inversión en activo fijo; $\mathrm{V}$ = ventas de activos fijos del ejercicio; $\mathrm{p}=$ índice de precios, ${ }^{28} \mathrm{y} \mathrm{d}=$ tasa de depreciación anual (inversa del período de vida útil). ${ }^{29}$

Las series de inversión no aparecen como tales en el balance. El rubro "Inversión" que se encuentra en el activo y hace referencia a las inversiones financieras y participaciones en otras empresas controladas y vinculadas. ${ }^{30}$ En cambio, la inversión en maquinaria y equipos se informa en el Anexo del balance, en el cuadro 1, según la disposición técnica de la FACPCE o cuadro de bienes de uso, con la forma de "Aumentos compras, mejoras permanentes, etc.". Ahí se detalla cada uno de los ítems que componen los bienes de uso: su valor original, las amortizaciones, los revalúos que podrían haber ocurrido, las ventas y aumentos por compras, mejoras o traspasos de un rubro a otro, ${ }^{31}$ y el resultado neto. A partir de este cuadro se pueden elaborar las series de inversión de los "aumentos" para cada rubro. ${ }^{32}$

${ }^{28}$ La fórmula está presentada en el trabajo de Guerberoff (1977: 502), quien toma los índices de los activos fijos y por eso menciona el stock revaluado a precios de reposición. Consideramos más adecuado tomar la variación de los precios del consumidor.

${ }^{29}$ Esta forma de calcularlo omite que los montos de inversión se realizan durante todo el año y entran de manera inmediata en el stock de capital, por lo cual comienzan a consumirse en ese momento. En la fórmula anterior, los flujos de inversión están considerados como un stock que sólo entra al comenzar el ejercicio siguiente. De esa manera subestima el stock de capital y el consumo de capital fijo de cada año, ya que la inversión que se realizó a mitad de año, recién tiene su impacto en el stock al finalizar el mismo. Una forma de ajustarlo sería tomar como stock de capital el promedio simple de los stocks de capital del ejercicio anterior y del que está en curso:

$$
C c f a_{t}=\frac{R_{t}+R_{t-1}}{2}
$$

donde: $\mathrm{Ccfa}=$ capital constante fijo adelantado y $\mathrm{R}=$ activo fijo valuado a precios históricos constantes. El límite de esta forma es que habría que recalcular el consumo del stock de capital con base en este nuevo stock. Otra forma de resolverlo podría ser considerar el promedio simple de la inversión del año anterior y del ejercicio en curso, y a partir de ese resultado revaluar el stock por medio del Método de Inventario Permanente. En este caso encontramos como límite deflactar por el índice de precios del año t la suma de inversiones de del año t y del t-1.

${ }^{30}$ Inversiones: “[...] son las realizadas con el ánimo de obtener una renta u otro beneficio, explícito o implícito, y que no forman parte de los activos dedicados a la actividad principal del ente [...] Incluyen entre otras: títulos valores, depósitos a plazo fijo en entidades financieras, préstamos", RT, núm. 9 de la FACPCE, cap. III, "Estado de situación patrimonial", punto A.2 (texto S/RT 31/2011).

${ }^{31}$ Los traspasos de rubros en general están relacionados con aquellas obras en construcción que finalizaron y por lo tanto se restan de ese rubro y se adicionan en el ítem correspondiente. Lo mismo ocurre con los equipos en viaje. Puede cambiar sustancialmente el análisis de la inversión si no se tienen en cuenta.

${ }^{32}$ Las series de compras y ventas de bienes de uso pueden estar presentados también en el cuadro de movimiento del flujo de caja, que sintetiza los movimientos de dinero. Sin embargo, podrían estar subestimadas debido a que en el caso en que la maquinaria fuera adquirida mediante un préstamo, bancario o del proveedor, no se asentaría en dicho cuadro. Al mismo tiempo, es posible que no distinga entre Instalaciones, maquinarias, rodados, etc. En ese caso se tendría que descartar ese dato, o habría que asignar una distribución de esa inversión en los diferentes rubros. 
También será importante para el revalúo considerar las ventas de cada uno de los rubros de los bienes de uso, debido a que de lo contrario podría considerarse una magnitud del stock de capital que ya no está presente en el proceso de producción. Tal como lo señalaba Guerberoff (1977), el límite que tiene esta información es que no presenta la vida útil restante del bien vendido. Por lo tanto estaremos restando al stock revaluado el monto de dinero al que fue vendido el bien, a precios de mercado, sin poder ajustarlo al valor residual del stock de capital.

Los flujos de inversión deben agruparse según la vida útil de los bienes para que luego inversiones de la misma clase sean amortizadas en la misma proporción. El balance no brinda información acerca de la vida útil de los bienes con los que cuenta la empresa, por lo que es necesario estimarla. Una forma de hacerlo sería a partir de estudios sectoriales, pero estos son escasos. Otra posibilidad sería tomar informes técnicos internos de la empresa o realizar entrevistas a técnicos especialistas. Algunos países, como Estados Unidos, poseen sistemas de cuentas nacionales que informan sobre la vida útil de la maquinaria utilizada en cada rama de la producción. De todas formas, las normas contables establecen una vida útil que se detalla en la tabla 1.

Una vez determinada la vida útil, es necesario definir a qué velocidad se consume el capital constante fijo y si ésta es uniforme o cambia a lo largo del tiempo. Es decir, qué distribución estadística seguirá el consumo del capital invertido. Existen diferentes distribuciones que son utilizadas. Las más frecuentes son: a) Lineal: supone que el capital fijo adelantado se consume de manera uniforme a lo largo de su vida útil; b) Geométrica: supone que el consumo es mayor en los primeros años de vida útil, y luego va decreciendo; c) Hiperbólica: asume que el consumo es mayor en los últimos años de vida útil; d) Rectangular: supone que la depreciación se efectiviza al final de su vida útil. Durante la vida útil, el valor del capital es igual al año inicial.

Como señala Coremberg (2004), la distribución rectangular corresponde a igualar el stock bruto con el neto. Por lo tanto sobreestima el stock de capital durante todos los años de la vida útil. En cambio, los manuales de medición del stock de capital de la OCDE recomiendan una distribución geométrica (OCDE, 2009) porque sería la mejor forma de reflejar cómo se deprecian los activos (con mayor velocidad al comienzo que al final). Tal como señalan Kornblihtt y Dachevsky (2011), la depreciación geométrica o hiperbólica podrá reflejar una mayor precisión en la depreciación, pero no en el consumo del capital. La depreciación hace referencia a la pérdida esperada del precio del activo en el mercado. Si bien esta disminución en el precio da cuenta del desgaste del bien, no es de manera precisa igual a medir el consumo del capital fijo. Lo que nos interesa analizar es en qué magnitud se transfiere el valor del capital constante fijo adelantado a la 
mercancía producida en el proceso de producción. Por esa razón, tanto para no agregar una distorsión más en el cálculo (como sería la distribución geométrica o hiperbólica), y debido a que refleja la misma intensidad con la que se usa la maquinaria, optamos por la depreciación lineal. ${ }^{33}$

Teniendo en cuenta una depreciación lineal y diferentes patrones de vida útil, Guerberoff (1977) agrupa las series de inversión en seis grupos diferentes (incluyendo terrenos y "otros activos"). En nuestro caso sugerimos la tabla 1. Por último, advertimos que en caso de que la apertura del cuadro 1 sea escasa, para la realización del cálculo sí es necesario como requisito mínimo discriminar entre inversiones en maquinaria y edificios industriales por ser aquellos en donde se concentra la mayor magnitud de las inversiones realizadas y donde la amplitud entre las diferentes vidas útiles es mayor.

Tabla 1. Activos fijos clasificados según período de vida útil

\begin{tabular}{lcc}
\hline Grupos bienes de uso & $\begin{array}{c}\text { Período de vida útil (d) } \\
\text { (años) }\end{array}$ & $\begin{array}{c}\text { Depreciación lineal } \\
\text { anual (1/d) (\%) }\end{array}$ \\
\hline Edificios & 50 & $2 \%$ \\
\hline Maquinaria & 20 & $5 \%$ \\
\hline Instalaciones, muebles y equipo de oficina & 10 & $10 \%$ \\
\hline Vehículos y herramientas & 7 & $14 \%$ \\
\hline
\end{tabular}

Fuente: elaboración propia en base a normas contables.

Cabe hacer una aclaración importante. Por la vida útil que se le asigna a las construcciones, este método debe aplicarse desde el primer año en el que la empresa comienza sus actividades o, en todo caso, acumular cincuenta años de inversiones para tener un primer resultado de stock confiable y método para estimarla. ${ }^{34}$

\footnotetext{
${ }^{33}$ Más allá de las diferencias en las distribuciones, en general todos los autores que miden la tasa de ganancia toman un criterio de consumo anual del capital adelantado. La excepción podría ser Shaikh (1999), quien toma la distribución rectangular afirmando que al capitalista le importa el valor total de la maquinaria como adelanto de capital, y no su valor depreciado (stock neto de capital).

${ }^{34}$ En caso de no contar con las series de inversión de la empresa desde el comienzo del ejercicio de la empresa, y como no es posible calcular los flujos de inversión para los años en que no hay datos, Guerberoff propone estimarla a partir de medir la sensibilidad del stock de capital de cada empresa durante los años en que no hay información. Lo hace a partir de considerar dos hipótesis arbitrarias en donde en una el stock se mantiene en precios corrientes y en otra se revalúa. Calcula la tasa de ganancia sobre estas dos series, y toma como primer año el año en el que convergen las dos (Guerberoff, 1977: 502-503).
} 


\section{El capital circulante adelantado (constante y variable)}

El capital constante circulante aparece con la figura de los bienes de cambio del activo dentro de la situación patrimonial de la empresa. Este tipo de bienes son los que posee la empresa para ser comercializados durante su actividad. Son aquellos que ella produce o que se adquieren para su reventa. Pueden encontrarse en el proceso de producción o distribución, ya sea en etapas iniciales o finales. Están constituidos por la mercadería comprada, las materias primas a utilizar, los productos elaborados y los bienes finales en venta.

Sobre la revaluación de los bienes de cambio existen diferentes posturas y metodologías sobre cuál es la mejor forma de reexpresar su valor. Mc Auly (1954) argumenta que frente a tasas recurrentes de inflación tiene una mayor aceptación el sistema denominado LIFO (último entrada, primero salida, por sus siglas en inglés, Last in, first out). Este sistema valoriza lo vendido a costos mayores y, por ende, arroja un menor cómputo en la ganancia, pero constituye un reaseguro frente a computar ganancias por inflación, como sostiene otro método de valuación como el "primero entrada, primero salida" (FIFO, por sus siglas en inglés, first in-first out) (Moonitz, 1954). Frente a estos dos métodos, Dagnino Pastore y De Pablo (1971) elaboran una propuesta que se basa en reexpresar los valores de los bienes de cambio a partir de coeficientes que tengan en cuenta la inflación y la rotación para cada uno de los rubros.

Por último, Guerberoff (1977), a fin de no agregar una distorsión más a los cálculos, desestima la revaluación de los bienes de cambio porque no es posible, a partir de la información de los balances, estimar el momento en el que fueron comprados y vendidos los inventarios.

Como lo que interesa en el proceso de valorización es el capital adelantado, es necesario considerar el capital constante circulante al comienzo del ejercicio. Para eso se tomará el monto de dinero del ejercicio anterior, que constituye el del comienzo del ejercicio en análisis. Otra forma de existencia del capital constante circulante son las disponibilidades, es decir, todos aquellos activos que se encuentran bajo la forma dineraria: dinero disponible en su caja y dinero en las cuentas corrientes de la empresa. En general aparecen bajo el rubro "caja y ban$\cos ^{\prime \prime} 35$ o "disponibilidades".

Este dinero es el que permitirá hacer las compras necesarias al comenzar el ejercicio. Iñigo Carrera señala que el capital circulante constante adelantado debe contemplar las dos formas en las que se puede encontrar, ya sea en su forma

\footnotetext{
${ }^{35}$ En este caso, habría que tomar sólo las cuentas bancarias corrientes o plazos fijos hasta treinta días. El dinero depositado en cuentas bancarias por encima de los treinta días no tendría que ser considerado necesariamente como dinero que va a ser utilizado en la compra inmediata de capital circulante (variable o constante).
} 
dineraria o mercantil (Iñigo Carrera, 996: 42). Por esa razón incluye la reserva de dinero disponible para la compra de materias primas y el valor de la materia prima que se adelantan al iniciar el ejercicio. ${ }^{36}$ En el caso de las disponibilidades, es preciso considerar el del ejercicio anterior debido a que ese será el monto con el que la empresa comience a operar en el siguiente año. Por otro lado, sería preciso incluir los documentos a pagar, ya que en general constituyen compromisos asumidos por la empresa por la adquisición de materias primas a sus proveedores. En este caso habría que considerar las del mismo período, ya que fueron mercancías adquiridas y aún no pagadas.

$$
K c c a_{t}=B s c_{t-1}+D i_{t-1}+C c v a+D p
$$

donde: $\mathrm{Kcca}=$ capital circulante constante adelantado; $\mathrm{Bsc}=$ Bienes de cambio; $\mathrm{Di}=$ Disponibilidades; $\mathrm{Ccva}=$ Capital circulante variable adelantado $\mathrm{Dp}=\mathrm{Do}-$ cumentos a pagar.

Una forma alternativa de estimarlo es partir del capital circulante consumido, calcular la velocidad de rotación durante el año, y así arribar al capital constante circulante adelantado. Para la estimación del capital circulante consumido se toma el costo de las mercaderías vendidas ${ }^{37}$ informado en el Estado de Resultado, depurándolo de las amortizaciones calculadas por el balance (consumo de capital fijo) y del capital variable consumido (salarios y cargas sociales pagadas):

$$
K c c c_{t}=C m v_{t}-A m_{t}-K v c_{t}
$$

donde: $\mathrm{Kccc}=$ capital circulante constante consumido $\mathrm{Cmv}=$ Costo de las mercaderías vendidas; $\mathrm{Am}=$ Amortizaciones calculadas por el balance, $\mathrm{y} \mathrm{Kvc}=\mathrm{ca}$ pital variable consumido.

Para la estimación de la velocidad de rotación, necesaria para esta otra forma de estimar el circulante adelantado, para un estudio de la economía estadounidense,

\footnotetext{
${ }^{36}$ Esto mismo es señalado en El capital (aunque en un capítulo escrito por Engels), en un análisis sobre el efecto de la rotación del capital sobre la tasa de ganancia: "De la caja, que contiene la parte del capital circulante que se halla en sus manos en forma de dinero [...] extrae el dinero para salarios; de la misma caja extrae el dinero para materias primas y auxiliares [...]. (Marx, 1999, t. III: 89.)

${ }^{37}$ Costo de los bienes vendidos y servicios prestados: "Es el conjunto de los costos medidos en valores corrientes del mes en que se reconocen, atribuibles a la producción o adquisición de los bienes o a la generación de los servicios cuya venta da origen a [los resultados] [...]", RT, núm. 9 de la FACPCE, cap. IV, "Estado de resultados", punto B.2 (texto S/RT 27/2009). En cuanto a su medición, se detalla que "el costo de un bien es el necesario para ponerlo en condiciones de ser vendido o utilizado, lo que corresponda en función de su destino. Por lo tanto, incluye la porción asignable de los costos de los servicios externos e internos necesarios para ello [...] además de los materiales o insumos directos e indirectos requeridos para su elaboración, preparación o montaje”, RT, núm. 17 de la FACPCE, cap. IV, "Medición contable en general”, punto 4.2.1 (texto S/RT 249/2002).
} 
autores como Fichtenbaum (1988) proponen tomar las ventas y dividirlas por el inventario total del sector. ${ }^{38}$

$$
n=\frac{V e_{t}}{K c c a_{t}}
$$

donde: $\mathrm{n}=$ rotación; $\mathrm{Ve}=$ Ingreso de los productos vendidos y $\mathrm{Kcca}=$ capital constante circulante adelantado.

Webber y Rigby (1986), en un estudio sobre la rama manufacturera canadiense, también parten de los inventarios para considerar el capital circulante adelantado. Lo interesante es que toman los inventarios como expresión del capital circulante adelantado, tanto variable como constante. Luego, con base en la proporción entre capital circulante constante consumido y capital circulante variable consumido, determinan cuánto capital variable adelantado se requirió. A partir de este método podemos estimar el capital variable adelantado en los balances debido a que no está presente como tal.

Según el grado de apertura que tenga el balance, y el período histórico en estudio, podría ser que el capital circulante variable consumido (ccvc) se detalle en el Estado de Resultados o en el cuadro I “Información”. También podría darse el caso de que esté informado en el cuerpo de las Memorias, en donde se detalla el gasto que se hizo en sueldos, jornales y cargas sociales. Asimismo puede presentarse la cifra de gastos en Honorarios a síndicos y retribuciones a directores de la empresa, que habría que depurar:

$$
c c v a_{t}=\frac{c c v c_{t}}{n}
$$

donde: $\mathrm{Ccva}=$ capital circulante variable adelantado $\mathbf{c c v c}=$ capital circulante variable consumido; $\mathrm{n}=$ rotación. Por lo tanto, la fórmula general del capital total adelantado quedaría:

$$
K T A_{t}=c c v a_{t}+c c c a_{t}+c c f a_{t}
$$

donde: KTA = capital total adelantado; $c$ cva $=$ capital circulante variable adelantado; $\mathrm{ccca}=$ capital circulante constante adelantado; $\mathrm{ccfa}=$ capital constante fijo adelantado.

\footnotetext{
${ }^{38}$ Consideramos que en este caso habría una sobreestimación de la rotación debido a que las ventas incluyen el capital constante fijo consumido y el capital circulante variable consumido. Para depurarlo, habría que tomar el capital constante circulante consumido calculado más arriba y dividirlo por el rubro bienes de cambio del ejercicio anterior.
} 


\section{Ganancias}

Las ganancias constituyen el resultado de la operación de adelanto de capital para el comienzo del proceso de producción y venta final de las mercancías elaboradas. En el balance, éstas se informan en el Estado de Resultados. Los resultados aparecen diferenciando entre los que son ordinarios y los que son extraordinarios. Según la RT, núm. 8 de la FACPCE, los ordinarios son los que se originan en las actividades habituales de la firma, mientras que los excepcionales o atípicos constituyen los resultados extraordinarios. ${ }^{39}$

Podemos distinguir tres tipos de ganancias en función de los diferentes análisis a realizar: la bruta, la neta y la final.

La ganancia bruta o ganancia operativa surge de las ventas realizadas menos el costo de las mercaderías vendidas. Este costo sólo incorpora el capital consumido en la fase de producción (fijo y circulante constante y variable), por lo tanto es una ganancia general que indica la marcha de la fase de producción en sentido restringido:

$$
\text { G bruta }=\text { Ve }-C m v
$$

donde: $\mathrm{G}$ bruta = ganancia bruta; $\mathrm{Ve}=$ ingreso de los productos vendidos, $\mathrm{y}$ $\mathrm{Cmv}=$ costo de las mercaderías vendidas.

La ganancia neta está constituida por la ganancia bruta descontados los gastos de comercialización, ${ }^{40}$ administración y distribución:

$$
G \text { neta }=G \text { bruta }-g c-g d
$$

donde: $\mathrm{G}$ neta = ganancia neta; $\mathrm{G}$ bruta = ganancia bruta; $\mathrm{gc}=$ gastos comerciales, y gd = gastos de distribución. ${ }^{41}$

\footnotetext{
${ }^{39}$ Diversos autores plantean que esta clasificación no es la más adecuada para consignar los resultados. Según Fowler Newton (2001: 1168) los ordinarios deberían ser los resultados regulares o comunes, mientras que los extraordinarios los atípicos e infrecuentes en el pasado. El punto tiene relevancia porque existen ingresos regulares que no brotan de la actividad principal de la empresa, por ejemplo, los alquileres o la venta de activos no destinados a la venta. Este mismo criterio es el que presenta Biondi (1993: 690).

${ }^{40}$ Gastos de comercialización: "Son los realizados por el ente en relación directa con la venta y distribución de sus productos o de los servicios que presta" (punto B. 5). En cambio, Gastos de administración: "Comprende los gastos realizados por el ente en razón de sus actividades, pero que no son atribuibles a las funciones de compra, producción, comercialización, investigación y desarrollo y financiación de bienes o servicios” (punto B.6), RT, núm. 9 de la FACPCE, cap. IV, “Estado de resultados” (texto S/RT 27/2009).

${ }^{41}$ Esta ganancia podría equiparase con la llamada EBIT (beneficios antes de impuestos e intereses por sus siglas en inglés).
} 
En cambio, la ganancia final descuenta los impuestos, las ganancias o pérdidas de actividades secundarias de la compañía, las ganancias no distribuidas de ejercicios anteriores, la distribución de dividendos y las ganancias o pérdidas de inversiones que tenga la empresa en otras empresas:

$$
\text { G final }=G \text { neta } \pm G v(P v)-i i-i-d
$$

donde: $\mathrm{G}$ final = ganancia final; $\mathrm{G}$ neta $=$ ganancia neta; $\mathrm{Gv}=$ ganancias varias $/ \mathrm{Pv}=$ pérdidas varias; $\mathrm{i}=$ Impuestos; $\mathrm{i}$ = intereses; $\mathrm{d}=$ distribución de dividendos.

Tal como vemos, tanto la ganancia neta como la final parten de la ganancia bruta, pero la ganancia bruta se constituye a partir de las ventas menos los costos de producción, y éstos contienen el consumo del capital fijo antes de la revaluación del stock que propusimos. Es decir, el costo de las mercaderías vendidas está calculado con las amortizaciones de un stock de capital que no refleja el valor real de los bienes, tal como señalamos más arriba. Por eso mismo es necesario ajustar las ganancias.

Es necesario recalcular las ganancias con el nuevo consumo de capital fijo. Para eso se establece la diferencia entre las amortizaciones calculadas por el balance y el consumo del stock de capital revaluado por el Método de Inventario Permanente (MIP). Esa diferencia se va a adicionar o a restar de las ganancias según sea el caso: ${ }^{42}$

$$
đ A m=A m-A m r
$$

donde: đAm: Diferencia del cálculo de amortizaciones; Am = amortizaciones calculadas por el balance; $\mathrm{Amr}=$ amortizaciones recalculadas a partir del MIP.

Otro elemento que afecta a las ganancias son las provisiones y previsiones que se imputan en el Estado de resultados. Estos son rubros que se utilizan para afectar los estados financieros por un posible gasto o ingreso de dinero originado en el ejercicio en curso, pero que tendrá incidencia en el siguiente ejercicio. Según entrevistas realizadas a contadores, éstas pueden ser una forma de disminuir la ganancia o la pérdida obtenida en un ejercicio a fin de tributar menos impuestos, por ejemplo. Por eso mismo es necesario depurar las ganancias de posibles provisiones y previsiones que aparecen en los estados de resultados.

\footnotetext{
${ }^{42}$ Nótese que aquí adicionamos o sustraemos la diferencia entre el consumo de capital calculada, por el balance bajo la forma de Amortizaciones, y el consumo de capital revaluado a través del MIP. No agregamos de manera simple las amortizaciones y depreciaciones como sugiere la conocida fórmula del EBITDA (beneficios antes de interés, impuestos, depreciación y amortización, según sus siglas en inglés).
} 
De esta forma, a partir de los ajustes implementados, las ganancias quedan constituidas de la siguiente manera:

$$
G a=G \text { neta (final) } \pm đ A m \pm P
$$

donde: $\mathrm{Ga}=$ ganancia ajustada; $\mathrm{G}$ neta (final) = ganancia neta o ganancia final; $đ A m=$ diferencia del cálculo de amortizaciones; $\mathrm{P}=$ provisiones / previsiones aplicadas al estado de resultados.

Un elemento importante para la comparación de tasas de ganancia de diferentes capitales, sobre todo de diferentes países, es incorporar el análisis de los impuestos. Se puede distinguir la ganancia final antes y después de impuestos pagados elaborando una serie de impuestos ${ }^{43}$ que se detallan en Estado de resultados y en el cuadro I "Información":

$$
\text { Ga final } i=\text { Ga final }+i i
$$

donde: $\mathrm{G}$ final $\mathrm{i}$ = Ganancia ajustada final antes de impuestos; $\mathrm{G}$ final = Ganancia ajustada final y ii = impuestos.

\section{Tasa de ganancia del capital individual}

A partir del desarrollo anterior, tanto del capital adelantado como de las ganancias obtenidas, la tasa de ganancia del capital individual estará dada por:

$$
G_{t}^{\prime}=\frac{\text { Ga neta }_{t}}{\operatorname{KTA}_{t-1}}
$$

donde: $\mathrm{G}^{\prime}=$ tasa de ganancia del capital individual; Ga neta = ganancia ajustada neta, y KTA = capital total adelantado.

Esta es una tasa de ganancia que permite equiparase con el capital total adelantado de la sociedad. La ganancia está depurada de todos los gastos necesarios para poner en marcha en negocio y el stock incorpora lo desembolsado en capital constante (fijo y circulante) y variable. ${ }^{44}$

\footnotetext{
${ }^{43}$ Diferentes estudios intentan llegar a la tasa de ganancia "social" a partir de considerar los impuestos en la tasa de ganancia de un agregado de capitales individuales. Ese es el caso del estudio de Petrei (1973) y Reca y Verstraeten (1981).

${ }^{44} \mathrm{Si}$ bien no es el objeto de este trabajo, se menciona que sobre esta base se calculó la tasa de ganancia para Siderca, empresa del grupo Techint, la cual arrojó en promedio $10 \%$ para el período 1959-1989, mientras que el margen sobre ventas da como resultado $28 \%$ para el mismo período.
} 


\section{CONCLUSIÓN}

En este trabajo nos propusimos abordar la cuestión de la metodología necesaria para estimar la tasa de ganancia de un capital individual industrial en Argentina, a partir de los balances elaborados por la propia empresa. El objeto general de establecer esta metodología es poder dar cuenta de la capacidad de valorización de los capitales individuales que acumulan en este espacio nacional.

Para eso se revisaron las determinaciones generales de la tasa de ganancia y se enfrentaron a otras medidas de rentabilidad más difundidas, como los márgenes sobre costos o ganancias. El resultado fue que los márgenes no dan cuenta de la rotación del capital, al considerar sólo el capital consumido como punto de partida, y no el capital adelantado.

$\mathrm{Al}$ mismo tiempo se reseñaron los principales trabajos que se plantearon la tarea de cuantificar la valorización del capital individual, desde los estudios sobre las haciendas en el Río de la Plata a fines del siglo XVIII hasta la actualidad. A partir de esto, nos enfrentamos a las principales dificultades metodológicas que ofrece el trabajo con balances contables.

El principal de ellos fue reestimar el stock de capital, debido a que las cifras aparecen distorsionadas como consecuencia de las altas tasas de inflación. Ello demandó recalcular el consumo del capital fijo y la ganancia obtenida. Se construyeron distintas series de inversión según la vida útil de los bienes y a partir del Método de Inventario Permanente estimar un nuevo capital constante fijo. De manera simultánea se considera una discusión para estimar la rotación del capital circulante y sus implicancias. Sobre esta base consideramos que es posible superar los límites que tienen los balances contables para dar cuenta de la tasa de ganancia del capital individual.

\section{REFERENCIAS BIBLIOGRÁFICAS}

Adrogué, María de la Paz y Anido, Marcela (1998), Análisis de acciones, Instituto Argentino de Mercado de Capitales. Buenos Aires.

Agostino, Rodrigo Javier (2015), "La tasa de ganancia en la Argentina de la posconvertibilidad (2002-2012)”, Revista Realidad Económica, núm. 291.

Amaral, Samuel (1989), Producción y mano de obra rural en Buenos Aires colonial: la Estancia de Clemente López Osornio, 1785-1795. Instituto Torcuato Di Tella, Centro de Investigaciones Sociales, Buenos Aires.

Arnaudo, Aldo (1965), "Comportamiento de los márgenes de beneficio del sector manufacturero en Argentina durante el período 1956-1964”, Reunión Anual de la Asociación Argentina de Economía Política (AAEP), AAEP, Mendoza, p. 24. 
Arnaudo, Aldo (1975), "Rentabilidad de empresas e inflación”, $10^{\circ}$ Reunión Anual de la Asociación Argentina de Economía Política, Universidad de Mar del Plata, Mar del Plata.

Auly, Mack (1954), "La inflación y la empresa”, Revista de Ciencias Económicas, núm. 49 , serie III.

Azpiazu, Daniel y Schorr, Martín (2010), Hecho en Argentina. 1976-2007, Siglo XXI, Buenos Aires.

Barrera, Mariano (2013), "Beneficios extraordinarios y renta petrolera en el mercado hidrocarburífero argentino", Desarrollo Económico, pp. 169-194.

Bas, Carlos y Carllinni, Néstor (1987), Rentabilidad de las explotaciones agrícola-ganaderas de la región pampeana, C. F. d. Inversiones, Buenos Aires.

Bil, Damián y Farfaro Ruiz, Betania (2012), "Aproximación a la medición de la renta petrolera argentina y sus mecanismos de transferencia (1963 a la actualidad)", $V$ Jornadas de Economía Crítica, Sociedad de Economía Política, Buenos Aires.

Bil, Damián y Bastida Bellot, Jonathan (2016), "Midiendo la rentabilidad de la industria argentina. Un ejercicio con las ramas autopartista y automotriz durante el período de sustitución (1948-1967)", Ciclos en la Historia, la Economía y la Sociedad, vol. 22, núm. 44.

Biondi, Mario; Biondi, Mario hijo, et al. (1993), Tratado de contabilidad intermedia y superior, Ediciones Macchi, Buenos Aires.

Brown, Jonathan (1978), "A Nineteenth-Century Argentine Cattle Empire", Agricultural History, vol. 52, núm. 1.

Castellani, Ana (2009), Estado, empresa y empresarios: la construcción de ámbitos privilegiados de acumulación entre 1966 y 1989, Prometeo, Buenos Aires.

Coremberg, Ariel (2004), Estimación del stock de capital en Argentina. Fuentes, métodos y resultados, Dirección Nacional de Cuentas Nacionales, en: http.// www. mecon. gov. ar/secpro/dir_cn/stock_capital. htm.

Chandler, Alfred (1996), Escala y diversificación: la dinámica del capitalismo industrial, trad. al esp. Beltran, Jordi, Prensas Universitarias, Zaragoza, Zaragoza.

Dachevsky, Fernando y Kornblihtt, Juan (2011), Aproximación a los problemas metodológicos de la medición de la tasa de ganancia y la renta de la tierra petrolera, Documentos de Jóvenes Investigadores.

Dagnino Pastore, José María y De Pablo, Juan Carlos (1971), Metodología para la revaluación de bienes de cambio, FIEL, Buenos Aires.

De la Fuente, Gabriel (2011), Compendio de finanzas aplicadas, Errepar, Buenos Aires.

De Pablo, Juan Carlos (1975), "Sobre la rentabilidad real de la industria argentina: una crítica a la estimación de Petrei”, Boletín Informativo Organización Techint, núm. 197. 
Djenderedjian, Julio (2003), “ ¿Peones libres o esclavos? Producción rural, tasas de ganancias y alternativas de utilización de mano de obra en dos grandes estancias del sur del litoral a fines de la colonia", Terceras Jornadas de Historia Económica, pp. 1831-1850.

Duménil, Gerard y Lévy, Dominique (2002), “The profit rate: where and how much did it fall? Did it recover? (USA 1948-2000)", Review of Radical Political Economics, vol. 34, núm. 4, pp. 437-46.

Féliz, Mariano (2011), Un estudio sobre la crisis en un país periférico: la economía argentina del crecimiento a la crisis, 1991-2002, El Colectivo, Buenos Aires.

Fichtenbaum, Rudy (1988), "Business Cycles', Turnover and the Rate of Profit: An Empirical Test of Marxian Crisis Theory”, Eastern Economic Journal, pp. 221-228.

Federación Argentina de Consejos Profesionales de Ciencias Económicas, FACPCE (varios años), Resoluciones técnicas contables (RT). Argentina.

FIEL (1971), La financiación de las empresas industriales en la Argentina. Análisis y aplicación de fondos en el período 1961-1969, 4 tt., FIEL, Buenos Aires.

Fitzsimons, Alejandro (2014), Estado y acumulación de capital en Argentina: la expansión de las empresas extranjeras entre 1958 y 1963, tesis doctoral, Universidad de Buenos Aires-Facultad de Ciencias Sociales, Buenos Aires.

Fowler Newton, Enrique (2001), Contabilidad superior, Macchi, Buenos Aires.

Garay, Jorge Osmar y Vangieri, Cyntia Juana (2013), Bienes de uso. Nuevas normas de medición contable, Universidad Nacional de Cuyo / FCE, Argentina, México. Grinberg, Nicolás (2011), Transformations in the Korean and Brazilian Processes of Capitalist Development between the mid-1950s and the mid-2000s: The Political Economy of Late Industrialisation, tesis doctoral, London School of Economics, London.

Guadagni, Alieto (1973), La rentabilidad empresaria: limitaciones de su medición, Centro de Investigaciones Económicas del Instituto Torcuato Di Tella, Buenos Aires.

Guerberoff, Simon (1977), "Un análisis de la performance del segmento industrial estable y su impacto en el modelo de crecimiento económico argentino (19491967)", Desarrollo Económico, vol. 16, núm. 64.

Halperin Donghi, Tulio (1975), Una estancia en la campaña de Buenos Aires, 17531809. Haciendas, latifundios y plantaciones en América Latina, Siglo XXI, México.

Harberger, Arnold (1969), "La tasa de rendimiento del capital en Colombia", Revista de Planeación y Desarrollo, vol. 1, núm. 3, pp. 3-42.

Iñigo Carrera, Juan (1992), Análisis de rentabilidad de plantaciones forestales tipo: rucalipto en la zona de Concordia y en la zona de Necochea, IICA/SAGyP, Buenos Aires. 
(1996), A Model to Measure the Profit Rate of Specific Industrial Capital by Computing their Turnover Circuits, Centro de Investigación para la Crítica Práctica (CICP), Buenos Aires.

(2007), La formación económica de la sociedad argentina, Imago Mundi, Buenos Aires.

(2007b), La mercancía, o la conciencia libre como forma de la conciencia enajenada, Imago Mundi, Buenos Aires.

(2008), El capital: razón histórica, sujeto revolucionario y conciencia, Imago Mundi, Buenos Aires.

Kliman, Andrew (2009), "Tras las huellas de la actual crisis económica y algunas soluciones propuestas”, Razón y Revolución, núm. 19.

Kornblihtt, Juan (2010), Acumulación de capital en Argentina a nivel internacional: la producción de tubos sin costura: origen y desarrollo de Siderca (19541989), tesis doctoral, Universidad de Buenos Aires-Facultad de Filosofía y Letras, Buenos Aires.

(2015), "Oil rent appropriation, capital accumulation, and social expenditure in Venezuela during chavism", World Review of Political Economy, vol. 6, núm. 1, pp. 58-74.

Levín, Pablo y Kicillof, Axel (1999), "Fundamentos del modelo de rotación del capital. El simulador de impacto ganancial”, Primeras Jornadas Interdisciplinarias de Estudios Agrarios y Agroindustriales, Buenos Aires.

Maito, Esteban (2013), "La Argentina y la tendencia descendente de la tasa de ganancia 1910-2011”, Revista Realidad Económica, núm. 275, pp. 127-152.

Mansilla, Diego (2006), "Una aproximación al problema de la renta petrolera en la Argentina (1996-2005)”, Realidad Económica, núm. 223, pp. 11-23.

Manzanelli, Pablo. (2010). "Evolución y dinámica de la tasa general de ganancia en la Argentina reciente”, Realidad Económica, núm. 256.

Marx, Karl (1999), El capital, Siglo XXI, México.

Mateo Tomé, Juan Pablo (2007), La tasa de ganancia en México, 1970-2003, Universidad Complutense de Madrid, Madrid.

Michelena, Gabriel (2009), "La evolución de la tasa de ganancia en la Argentina (1960-2007): caída y recuperación”, Realidad Económica, núm. 248, pp. 83-106.

Moonitz, Maurice (1954), "A Tentative Set of Broad Accounting Principies for Business Enterprises", Revista de Ciencias Económicas, vol. 48, núm. III.

Moseley, Fred (1997), "The rate of profit and the future of capitalism", Review of Radical Political Economics, vol. 29, núm. 4, pp. 23-41.

Mussi, Emiliano (2009), “Aproximación al problema de los límites del pequeño capital y su desarrollo en el sector autopartista de reposición nacional", Jornadas de Investigación y Debate Político, núm. II, Buenos Aires. 
NEDO (1973), Inflation and company accounts in Mechanical Engeneering, NEDO, London.

OCDE (2009), Medición del capital. Manual, OCDE, París.

Parada, Ricardo y Errecaborde, José Daniel (2015), Resoluciones técnicas vigentes, Federación Argentina de Consejos Profesionales de Ciencias Económicas, Buenos Aires.

Pérez Artica, Rodrigo (2009), "Un enfoque micro del ciclo posconvertibilidad. Los casos de Acindar, Aluar y Siderar", Realidad Económica, núm. 246, pp. 105-126.

Petrei, Amalio Humberto (1973), "Rates of return to physical capital in manufacturing industries in Argentina", Oxford Economic Papers, vol. 25, núm. 3, pp. 378-404.

Recalde, Marina (2012), "Los recursos energéticos en Argentina: análisis de la renta", Problemas del Desarrollo, vol. 43, núm. 170, pp. 9-37.

Reca, Lucio y Verstraeten, Julio (1981), "La tasa social de retorno al capital en la Argentina (1935-1973)”, Económica, núm. 27.

Robles Báez, Mario (2013), "La posición del capital como muchos capitales y como capital social total y la determinación de las tasas uniforme y general de ganancia”, Razón y Revolución, núm. 23.

Samuelson, Paul y William Nordhaus (2002), Economía, 17 ed., McGraw-Hill, Madrid.

Shaikh, Anwar (2006), Valor, acumulación y crisis, Ediciones ryr, Buenos Aires.

Shaikh, Anwar (1999), "Explaining the global economic crisis", Historical Materialism, vol. 5, núm. 1, pp. 103-144.

Shaikh, Anwar y Ahmet Tonak (1997), Measuring the wealth of nations, Cambridge Books, London.

Sourrouille, Juan (1980), El complejo automotor en Argentina: transnacionales en América Latina, Instituto Latinoamericano de Estudios Transnacionales, Buenos Aires.

Valenzuela Feijóo, José (2009), La gran crisis del capital. Trasfondo estructural e impacto en México, UAM, México.

Vitelli, Guillermo (1986), Cuarenta años de inflación en la Argentina: 1945-1985, Legasa, Buenos Aires.

Webber, Michael y Rigby, Daniel (1986), “The rate of profit in Canadian Manufacturing, 1950-1981”, Review of Radical Political Economics, vol. 18, núm. 1-2, pp. 33-55. 